NASA Technical Memorandum 105215

\title{
Description of Liquid Nitrogen Experimental Test Facility
}

(NASA-TM-105215) DESCRIPTION OF LIQUIO

$\stackrel{-1}{-} \quad$ ITR
$-\quad 14 \mathrm{P}$

$*=$
(NASA)

CSCL $20 I$
N92-11208

Unclas

$63 / 28 \quad 0047538$

John M. Jurns

Sverdrup Technology, Inc.

Lewis Research Center Group

Brook Park, Ohio

Richard E. Jacobs

Analex Corporation

Brook Park, Ohio

and

Naseem H. Saiyed

National Aeronautics and Space Administration

Lewis Research Center

Cleveland, Ohio

September 1991 

. 


\title{
DESCRIPTION OF LIQUID NITROGEN EXPERIMENTAL TEST FACILITY
}

\author{
John M. Jurns \\ Sverdrup Technology, Inc. \\ Lewis Research Center Group \\ Brook Park, Ohio 44142 \\ Richard E. Jacobs \\ Analex Corporation \\ Brook Park, Ohio 44142 \\ and \\ Naseem H. Saiyed \\ National Aeronautics and Space Administration \\ Lewis Research Center \\ Cleveland, Ohio 44135
}

\begin{abstract}
The Liquid Nitrogen Experimental Test Facility is a unique test facility for ground-based liquid nitrogen experimentation. The test rig consists of an insulated tank of approximately $12.5 \mathrm{ft}^{3}$ in volume, which is supplied with liquid nitrogen from a 300 gal dewar via a vacuum jacketed piping system. The test tank is fitted with pressure and temperature measuring instrumentation, and with two view ports which allow visual observation of test conditions.

To demonstrate the capabilities of the facility, the initial test program is briefly described. The objective of the test program is to measure the condensation rate by injecting liquid nitrogen as a subcooled spray into the ullage of a tank 50 percent full of liquid nitrogen at saturated conditions. The condensation rate of the nitrogen vapor on the subcooled spray can be analytically modeled, and results validated and corrected by experimentally measuring the vapor condensation on liquid sprays.
\end{abstract}

\section{INTRODUCTION}

The Cryogenic Fluids Technology Office (CFTO) is developing the technologies necessary for the efficient management of cryogenic fluids in space. The no-vent fill (NVF) technique is one such technology. Its purpose is to fill a given space-based tank with cryogenic fluids without venting while maintaining the tank pressure within allowable limits. A proposed technique to control the tank pressure is to fill the tank by injecting the liquid as a subcooled spray into the tank's ullage. Because the ullage condenses on the subcooled spray, the tank pressure increase is slowed during the NVF, and consequently, a higher tank fill level can be achieved for any given tank pressure.

The success of using subcooled spray to achieve NVF strongly depends upon the condensation of vapor on the subcooled spray. Therefore, it is imperative that this condensation process be well understood and that the condensation rates be accurately predicted. Although experimental and analytical work has been done for the condensation of steam on water sprays, no analytical work has been done on cryogenic fluids. Nor do the existing studies consider the spray droplet heating due to forced convection from the vapor. An analytical model that 
considers such heating has been developed by NASA Lewis Research Center engineers and is currently being validated by vapor condensation experiments being conducted at the Liquid Nitrogen Experimental Test Facility (RL-13),

This report presents a detailed description of the test facility and its associated systems and instrumentation. Techniques employed for the acquisition and reduction of the test data are also outlined. Capabilities of the system are demonstrated by briefly describing planned vapor condensation experiments.

\section{EXPERIMENTAL FACILITY DESCRIPTION}

The Liquid Nitrogen Experimental Test Facility is located in Cell 13 of the Rocket Laboratory (RL-13) at NASA Lewis. Remote operation and monitoring functions are performed in a control room which is separated from the test cell by a concrete wall. The test rig can be viewed with a remotely controlled video camera inside the cell. All safety precautions required for testing cryogenic nitrogen have been incorporated into the test rig design and test procedures, making the facility well designed to accommodate liquid nitrogen testing.

Site

The test site consists of three components: (1) the nitrogen supply system outside the test cell, (2) the test hardware inside the test cell, and (3) the control room adjacent to the test cell. The nitrogen supply system outside the test cell consists of a $300 \mathrm{gal}$ dewar which supplies liquid nitrogen to the cell via a vacuum jacketed piping system and control valving. The test cell contains the test tank, vacuum jacketed supply piping, electric vaporizers, piping, controls, and instrumentation. The control room contains the instrumentation panels, data acquisition system and programmable logic controller (PLC). The PLC controls the test operation.

\section{Mechanical Hardware}

Spray nozzle testing in the RL-13 test facility is performed inside an insulated test tank. Liquid nitrogen is supplied to the test tank via vacuum jacketed piping connected to the $\mathrm{LN}_{2}$

dewar. A schematic of the spray nozzle test system is presented in figure 1 .

Test tank. - The test tank (figs. 6 to 8) consists of a 24-in. diameter cylindrical section capped by dished heads. A flange separates the upper dished head from the cylindrical section. Two 6-in. diameter access flanges provide fluid and instrumentation feedthroughs at the top and bottom of the tank assembly. Two 6-in. diameter quartz windows in the side of the tank provide viewports, and a 2 -in. diameter quartz window on the top head of the tank provides a video camera viewport. The tank assembly is supported on three legs, which are bolted to the floor of the test cell. Micarta insulated pads provide a thermal barrier between the tank legs and the concrete floor. The test tank is constructed of type 304 stainless steel and rated for use at 150 psig pressure at liquid nitrogen temperatures. All seals are suitable for use at liquid nitrogen temperatures. The quartz window viewports have an outer window of polycarbonate to provide a purged "frost-free" zone. The test tank is surrounded by a copper cold wall containing $\mathrm{LN}_{2}$ coils and is covered by insulation to establish and maintain the test tank wall at saturated $\mathrm{LN}_{2}$ temperatures as required by the test. 
$\underline{L N}_{2}$ supply dewar. - The supply dewar is a vacuum jacketed stainless steel tank containing perlite insulation within the vacuum annulus. This horizontal cylindrical tank is mounted on wheels for portability. It has a capacity of 300 gal net of $\mathrm{LN}_{2}$, and a maximum allowable working pressure of 150 psig. The dewar is self contained with a liquid fill and withdrawal line, vapor phase vent line, pressure building circuit, safety valve, bursting disk, liquid level indicator, and pressure indicator.

Vacuum jacketed piping. - The liquid nitrogen supply piping is a vacuum jacketed stainless steel line which transfers liquid nitrogen from the 300 gal supply dewar to the test tank. The jacketed line running from the dewar is split into three streams: the first is connected to the bottom of the test tank and is used to fill the tank; the second is connected to the spray nozzle line in the top of the test tank; and the third provides liquid to a $9 \mathrm{~kW}$ vaporizer which in turn provides cold vapor to the test tank. The first two lines can fill the tank from the bottom or top, either separately or simultaneously. Flow of liquid through each of these lines is controlled by pneumatically actuated, vacuum jacketed valves. Flow is measured by vacuum jacketed venturi flowmeters installed in the lines.

Venturi flowmeters. - There are three vacuum jacketed venturi flowmeters in the system. Below is a listing of the flowmeters, their label, the maximum flowrates, and dimensional information.

\begin{tabular}{lcc}
\multicolumn{1}{|c}{ Venturi } & $\begin{array}{c}\text { Maximum } \\
\text { flow rate, } \\
\text { lb/hr }\end{array}$ & $\begin{array}{c}\text { Throat } \\
\text { diameter, } \\
\text { in. }\end{array}$ \\
$\begin{array}{l}\mathrm{LN}_{2} \text { spray } \\
\text { into tank }\end{array}$ & 1000 & 0.150 \\
$\begin{array}{l}\mathrm{LN}_{2} \text { fill } \\
\text { (bottom) }\end{array}$ & 150 & .150 \\
$\begin{array}{l}\text { GN2 cold } \\
\text { vapor }\end{array}$ & 125 & .080
\end{tabular}

The venturi flowmeters are constructed with the same overall dimensions and are interchangeable. An additional spare venturi with a throat diameter of $0.200 \mathrm{in}$. is also available for a different range of flow rates.

Tank vacuum system. - The test tank vacuum system consists of a mechanical vacuum pump rated at $53 \mathrm{ft}^{3} / \mathrm{min}$. The pump communicates with the vapor phase piping and performs three functions. It removes air and moisture from the test system before the system is charged with liquid nitrogen; it provides vent capability for sub atmospheric test operations; and it can reduce pressure in the supply dewar to sub-cool the liquid nitrogen supply.

Vent system. - The vent system provides a means of controlling the pressure inside the test tank as well as providing for over pressure protection and venting of the test tank. Pressure control is provided by a pneumatically operated control valve which is driven by a proportional and integral (PID) process controller that senses tank pressure and modulates the valve accordingly to maintain the desired pressure set point. The tank can also be pressurized with either 
nitrogen or helium using a dome-loaded pressure regulator. Over pressure protection is provided by a safety relief valve set at 120 psig, with a secondary back up provided by a frangible bursting disk set at 150 psig. Tank venting is provided for by either a dome-loaded pressure regulator, which allows tank pressure to be vented to a set value, or by a pneumatically operated ball valve, which allows the tank to be vented to atmospheric pressure.

Vaporizer and gas heaters. - The test rig includes one $9 \mathrm{~kW}$ electric vaporizer which supplies cold nitrogen vapor to the ullage in the test tank. Vapor temperature is controlled by a variable voltage power controller which takes its input signal from a PID controller. There are also two $5 \mathrm{~kW}$ gas heaters in the vent piping system used to warm vapor from the test tank to ambient temperature. The heaters are thermostatically controlled on/off operation. This is required to protect piping and components in the vent system which are not rated for cryogenic service. A $400 \mathrm{~W}$ resistive tape heater is wrapped around the inlet line of the vacuum pump to protect it from low gas temperatures. Finally, there is a $1500 \mathrm{~W}$ resistive heater strapped to the test tank to aid in liquid boil off after testing is complete.

\section{Electrical System and Controls}

Electrical systems. - Power circuits are provided for five heaters and one $3 \mathrm{hp}$ vacuum pump. One heater, the $\mathrm{LN}_{2}$ vaporizer, and the vacuum pump require three-phase power. The remaining heaters require only single-phase power.

Power is also supplied for control circuits. Twenty-four volt dc control power is provided for solenoid valves (to minimize signal noise) and for the programmable logic controller. Onehundred-ten volt ac power is provided for panel instrumentation and process controllers.

Controls. - Test rig controls are grouped on three instrument racks in the control room for ease of test operation. The control racks consist of a graphics control panel, pushbuttons, and display meters (fig. 5). Commands to control the test rig operation are entered on the graphics control panel which contains on/off push buttons, potentiometers, and status indication lights. System temperatures and pressures are displayed on digital panel meters.

A programmable logic controller is utilized to control operation of the test system. Inputs to the controller are from either pushbuttons on the graphics control panel in the control room, or from relay contacts on system controllers or indicators. Outputs from the controller drive relays which in turn actuate valves or enable control devices to operate the system.

\section{Instrumentation}

The instrumentation system for the test rig is comprised of sensors for temperature, pressure and flow measurement. Instrumentation signal wiring is routed to the control room with shielded cabling run in instrumentation trays separated from the power supply to minimize signal noise.

Temperature measurement. - Temperature sensors are positioned throughout the test rig on the test tank and selected lines and components. Temperature measurements are obtained with both thermocouples and platinum resistance temperature detectors (RTD). 
Twenty thermocouples are located on the exterior surface of the test tank wall, spaced strategically to indicate tank wall temperatures (fig. 2). There are also 14 thermocouples on the copper cooling coil jacket to measure the temperature of the jacket.

The tank contains two temperature rakes. The first is inserted in the top of the tank and has 17 thermocouples evenly spaced at 2.75 -in. intervals to determine the axial temperature distribution of the liquid and vapor in the tank (fig. 3). The second rake is inserted in the bottom of the tank and has three thermocouples spaced at 3.0-in. intervals. The bottom rake also contains one of the platinum RTDs to measure bulk liquid temperature in the bottom of the tank.

A second RTD measures the temperature of the spray nozzle $\mathrm{LN}_{2}$ inlet line immediately prior to its injection into the tank. A third RTD, mounted on an adjustable rake, measures the tank vapor temperature.

In addition to the tank wall and rake temperature measurements, other temperature sensors are placed in key locations throughout the test rig. Thermocouples are positioned in the vacuum jacketed liquid lines and vapor inlet lines, venturi inlets and nitrogen vapor vent lines.

Pressure measurement. - Pressure transducers provide continuous pressure data on the supply dewar, test tank, supply and vent lines. Static inlet pressure and pressure differential measurements are also measured on all venturi flowmeters.

Calibration of all the pressure sensors was confirmed prior to installation. On-line electrical calibrations are routinely performed and checked by instrument technicians prior to each test run.

Liquid level. - Liquid height as a percentage of total tank height is measured via a capacitance level probe. The probe is constructed of an outer and inner pipe which form an annular space where liquid and vapor accumulate. Holes are drilled in the outer pipe to allow inflow of liquid nitrogen into the annular space. The probe is mounted vertically within the tank, and capacitance measurements of the space between the pipes are made. The magnitude of the capacitance reading for a particular fluid is an indication of the fraction of liquid versus vapor resident in the annular space. In this way, the probe provides a measurement of the liquid height within the tank.

After the capacitance level probe was installed in the test tank, it was calibrated according the manufacturer's instructions. Zero and span adjustments were made by filling the test tank to 0 and 100 percent of the desired level. The probe does not extend to the bottom of the test tank, hence the zero on the probe corresponds with a liquid level in the tank of 8.0-in. This was confirmed visually with the video camera. The full span level was confirmed by comparing the probe measurement with the temperature measured on the thermocouple rake (liquid nitrogen temperature indicated at a thermocouple near the top of the tank). The full span level is 48.5-in. above the bottom of the tank.

Flow measurement. - Mass flow rate through each of the vacuum jacketed inlet lines of the test tank is measured with venturi flowmeters which are instrumented with temperature and pressure taps. In addition, there is a turbine flowmeter in the liquid drain line which measures the flow rate of liquid draining from the tank. 


\title{
DATA MANAGEMENT
}

\author{
Data Acquisition
}

Measurements in the form of voltage signals from the various sensors at RL-13 are transmitted to the ESCORT II data acquisition system at the Research Analysis Center (RAC building). The signal is transmitted through a signal conditioner (for voltage signals) and thermocouple reference oven (for thermocouple measurements) to a patch board, and then to a Neff multiplexer in the control room of the test cell. From the multiplexer, the signal is transmitted to a remote acquisition microprocessor (RAMP), and then to a DEC PDP 11/34 microcomputer in the RAC building.

There is a data acquisition program written specifically for the RL-13 facility, which provides not only the capability of acquiring data, but can also provide data recording, on line data display, limit checking, performance calculations, graphics and history files. The system has 165 channels available for scanning and recording data, and updates all data approximately every $2.5 \mathrm{sec}$.

\section{Data Display}

Data for the RL-13 facility is displayed on two cathode ray tube (CRT) monitors, an eight channel strip chart recorder, digital panel meters, video cameras, and a high speed $8 \mathrm{~mm}$ camera. One of the CRT monitors provides data for the research engineer and has five screens available to display pertinent parameters such as temperatures, pressures, flow rates, and liquid level. The other CRT monitor has only one screen and displays critical operating parameters for the operations engineer. The strip chart recorder provides a continuous trace of eight system parameters, such as liquid level, tank pressure, and differential pressure across flowmeters. Digital panel meters provide temperature and pressure measurements and monitor system conditions independent of the ESCORT II data acquisition system. Video cameras provide a view of conditions inside the test tank and are connected to a video cassette recorder for video taping. Finally, a high speed $8 \mathrm{~mm}$ camera is available to take high speed motion pictures of the spray.

\section{Data Reduction}

During a test run, ESCORT II displays real time data, updating displays for each scan. In addition, data can be recorded by transmitting it to the RAC building for subsequent retrieval and analysis. Transmission is accomplished in two different modes: the first mode records the entire 165 channels of data per one scan, the second mode records the first 60 channels continuously for a 10 min period. Digital signals transmitted to the RAC building are converted to engineering units and returned to the test cell display CRTs.

Calculated parameters. - Calculated values, such as flow rate through a venturi, are generated from user defined calculations or tables which have been input into the ESCORT II program.

The venturi flowmeters have been calibrated at the NASA Lewis flow lab using water for the liquid venturi, and air for the nitrogen vapor venturi. The flow calibration curves have been corrected for either liquids or gaseous nitrogen. The turbine flowmeter calibration curve was 
supplied by the vendor for water, and has also been corrected for liquid nitrogen. The tank level is derived from the capacitance level probe readings by transforming percent of full scale reading of the probe to inches of liquid level.

Data records and plots. - After data has been transmitted to the RAC building and recorded, it is available for post run plotting and analysis. Each data reading is identified by a unique reading number by which it can be accessed. Various parameters can be plotted by accessing a program named POSTPLOT on the NASA Lewis scientific VAX cluster. This interactive program allows plotting and editing of various parameters. Plots generated for this series of tests include plots of tank wall temperature, tank liquid and vapor temperature, venturi temperatures and pressures, tank pressures, liquid level in tank, and calculated flow rates.

\section{Safety}

Safety concerns and precautions. - The principal hazards associated with the operation of the test rig are rupture of the test tank or piping, leakage of nitrogen into the test cell and control room, and personnel contact with extremely cold surfaces. Each of these hazards has been addressed by incorporating certain design considerations and operational features into the rig that will reduce the probability of these hazards occurring and limit the severity of the effects if they do occur. These include:

(1) Tests are conducted with written procedures.

(2) Video scanning cameras permit remote observation of conditions in the test and minimize the need to enter the test cell during test operation.

(3) Instrument signals used for monitoring and control of the test are independent of the Escort data system. Test conditions are displayed by panel meters on the operator's console.

(4) The operator's graphic control panel incorporates status lights enabling monitoring of valve positions.

(5) An independent "Emergency Shutdown" system will be able to return the test tank and rig to a "fail-safe" status at the push of the operator's button. The "fail-safe" mode shuts off $\mathrm{LN}_{2}$ inflow, and opens the tank vent line.

(6) Low-oxygen detectors are located in the test cell and in the control room.

(7) If a low-oxygen level is detected, a remotely controlled vent fan will exhaust nitrogen vapors from the test cell.

\section{OBSERVATIONS AND DISCUSSION}

Tests have been completed to quantify the influence of various factors affecting the performance of the test rig. The following is a discussion of these tests.

Heat flux tests. - Heat flux tests were conducted to determine the total heat leak into the system from the ambient environment. These tests were conducted with and without the $\mathrm{LN}_{2}$ 
cold wall operating. For both tests, the test tank was cooled down, and filled to 90 percent with $\mathrm{LN}_{2}$. For the first test, $\mathrm{LN}_{2}$ was circulated through the cold wall cooling coils. The tank was allowed to vent to atmosphere, and the liquid level in the test tank versus time was recorded. The second heat flux test conducted was the same as the first, except no $\mathrm{LN}_{2}$ was circulated through the cold wall. Liquid level versus time was again recorded. The total liquid boiled off was plotted against time (fig. 4). The slope of this curve determined boil off rate in pounds per hour of $\mathrm{LN}_{2}$. This boiloff rate was then converted to Btu per hour heat leak because all of the $\mathrm{LN}_{2}$ remained at saturation.

The total steady state heat leak into the tank was determined to be approximately $1400 \mathrm{Btu} / \mathrm{hr}$ with the cold wall operating.

\section{CONCLUDING REMARKS}

The liquid nitrogen experimental test facility has proven useful in revealing some aspects of $\mathrm{LN}_{2}$ spray through nozzles that otherwise may have gone unnoticed. The test facility should also prove versatile in other cryogenic testing. Injection or mixing tests for liquid nitrogen or nitrogen vapor can be conducted at the facility, and processes can be characterized visually by the unique ability to view inside the test tank. Test articles can be inserted through ports in the test tank and subjected to cryogenic conditions. Many tests requiring the use of liquid nitrogen as a test fluid or cryogenic environment could be performed at this facility, assuming the geometry of the test tank is adequate. 


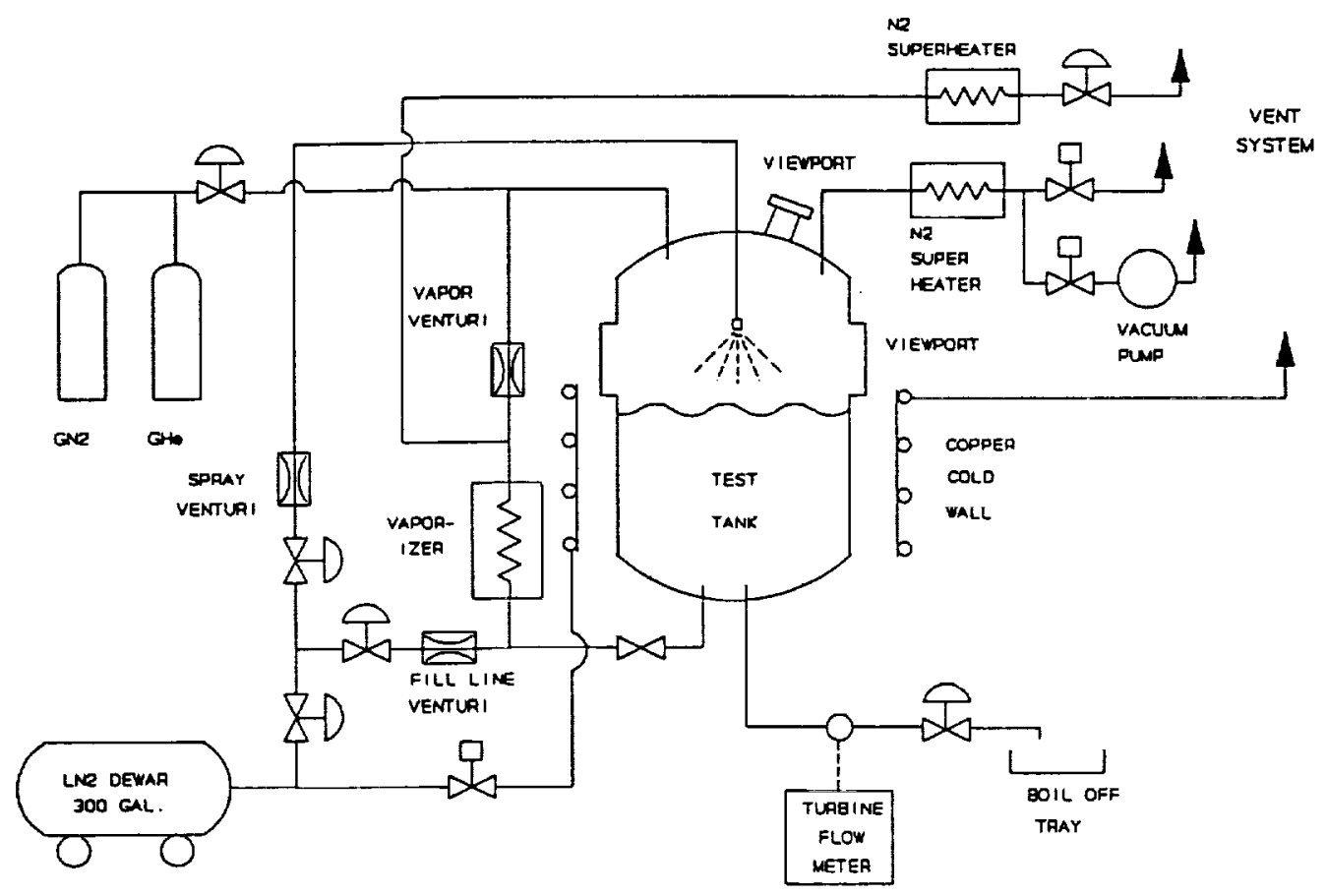

RL- 13 LN2 TEST FACILITY

Figure 1. - Simplified flow schematic.
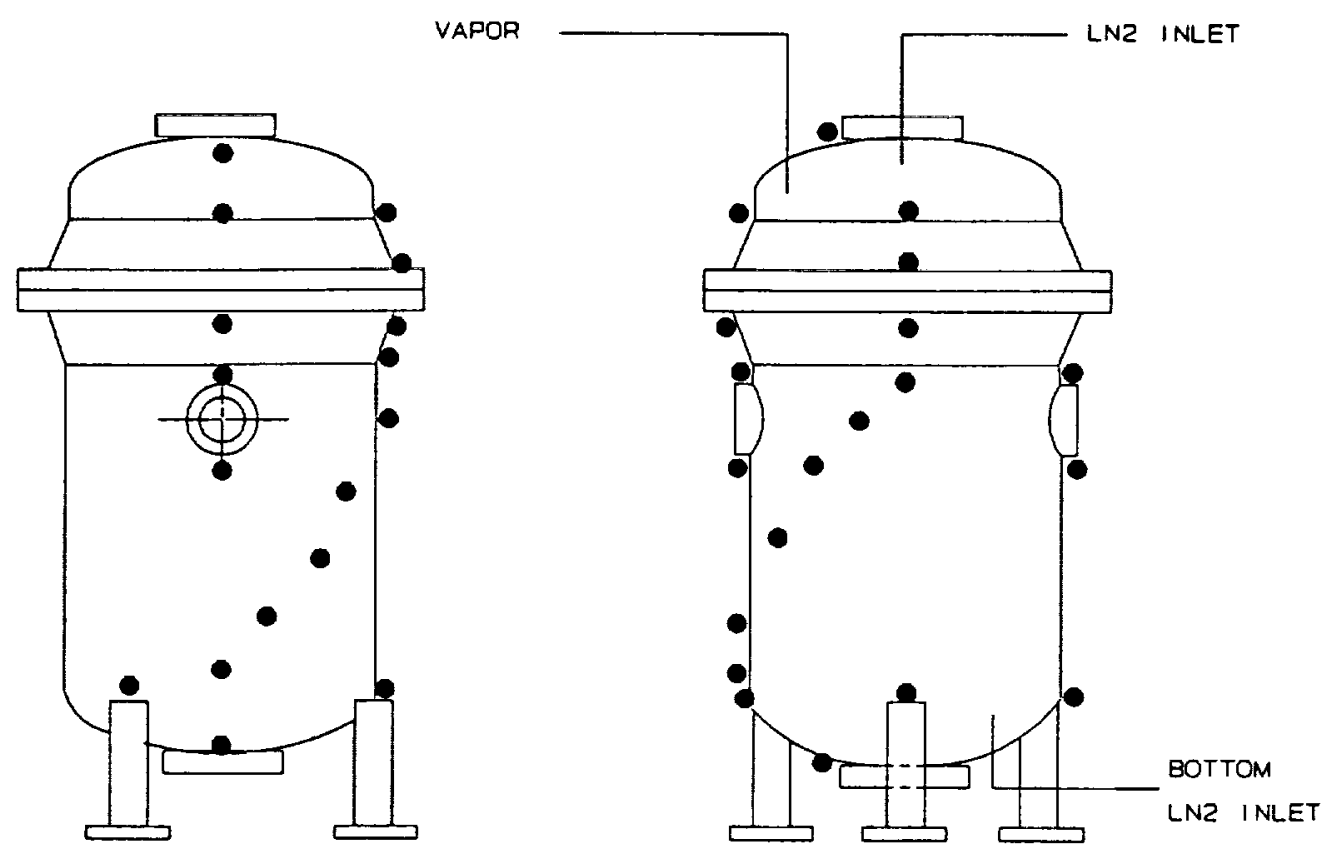

- Tank wall thermocouples (not to scale)

Note: Some thermocouples may over lap between the two views.

Figure 2. - Thermocouple distribution on the tank wall. 


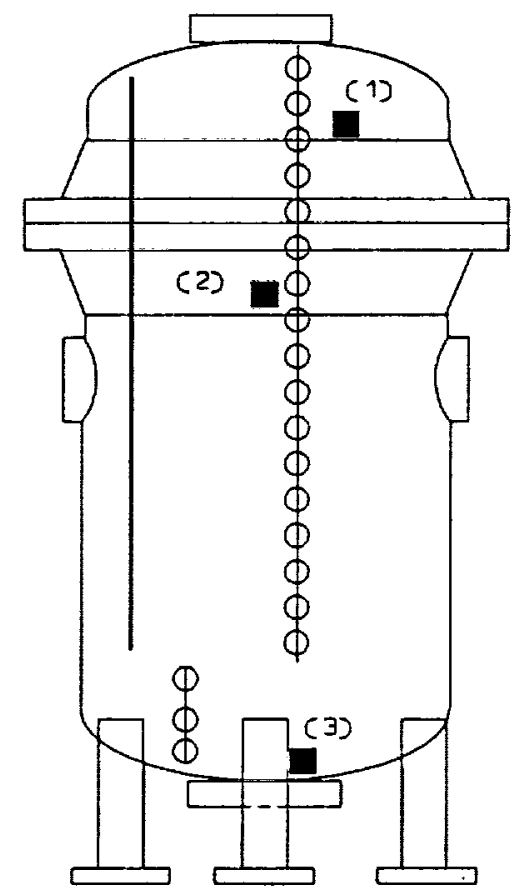

- RTO 's: (1) Tank vapor (adjustable)

(2) Spray nozzle

(3) Tank bulk liquid

- Rake thermocouples

- Liquid level sensor

Figure 3. - Instrumentation inside the tank.

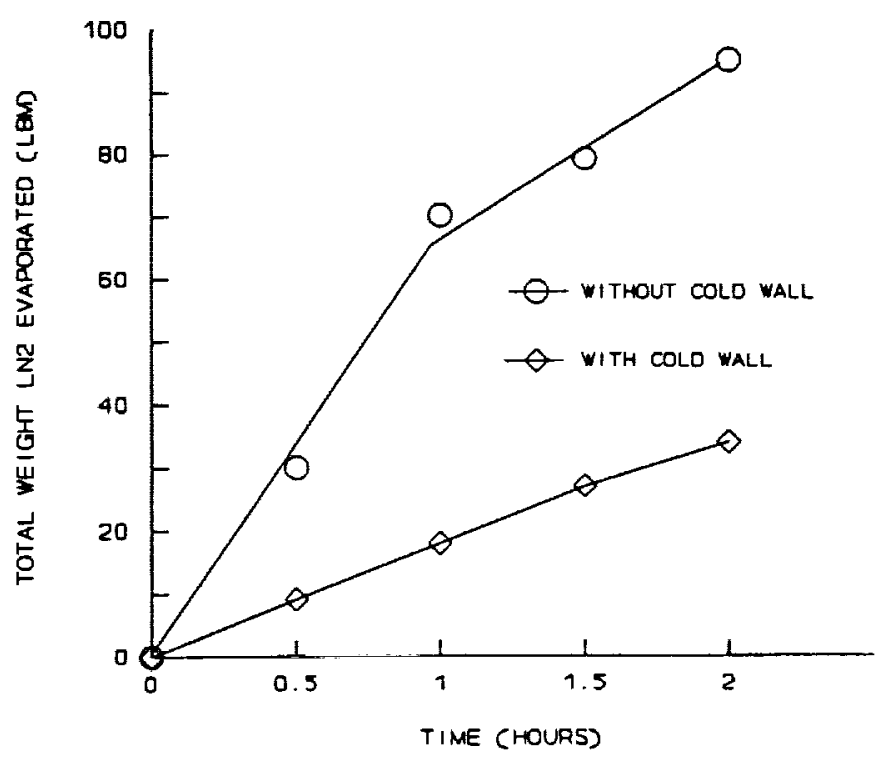

Figure 4. - Liquid nitrogen boil off versus time RL-13 LN2 test rig. 
BLACK AND WHITE PHOTOGRAPH

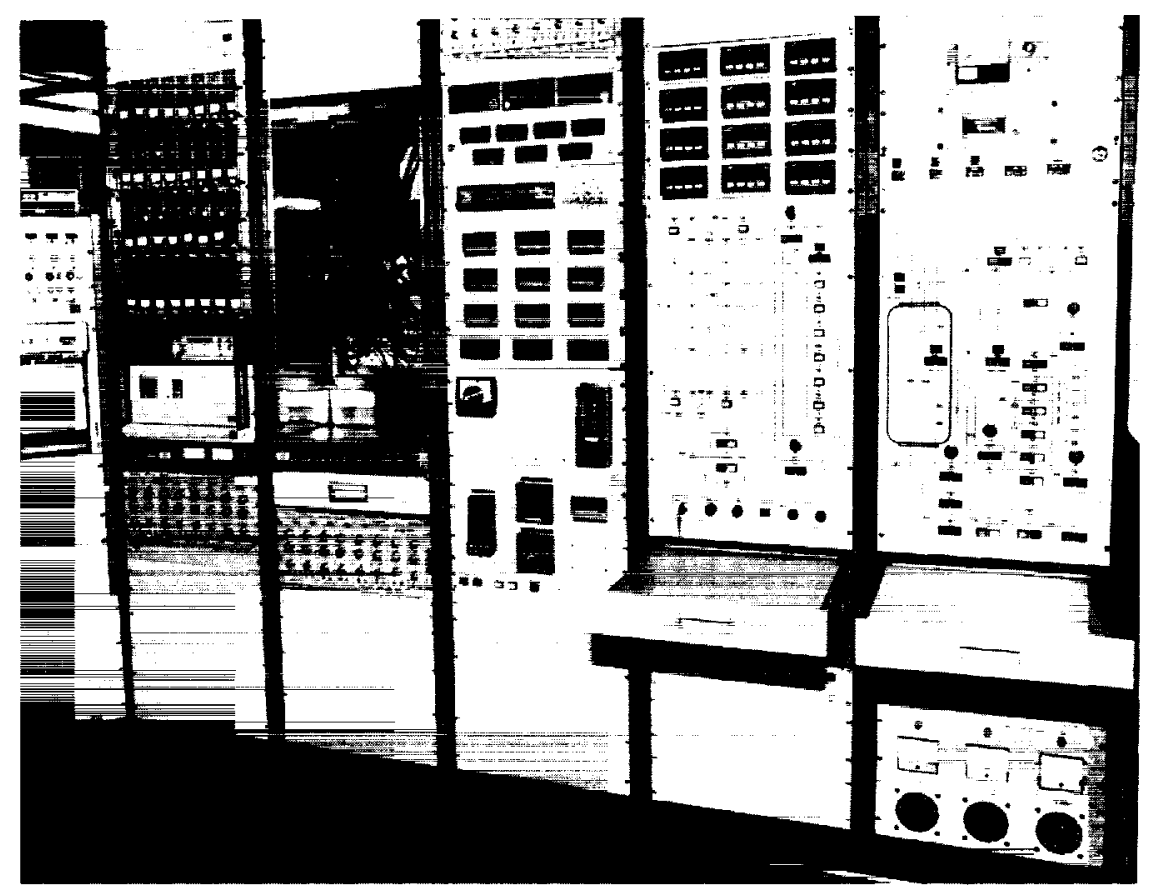

Figure 5. - Instrumentation and graphics control panel.

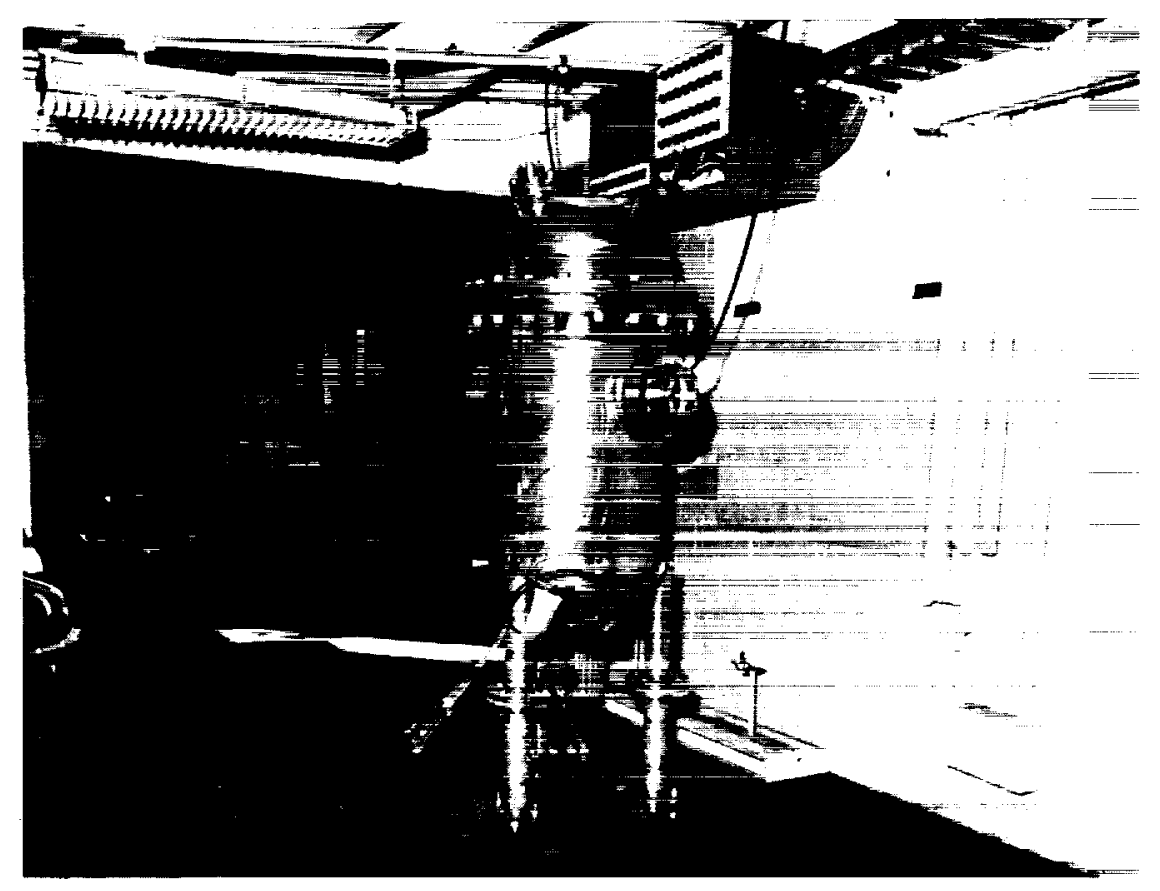

Figure 6. - Test tank (without cold wall or insulation). 
ORIGINAL FRGE

BLACK AND WHITE PHOTOGRAFH

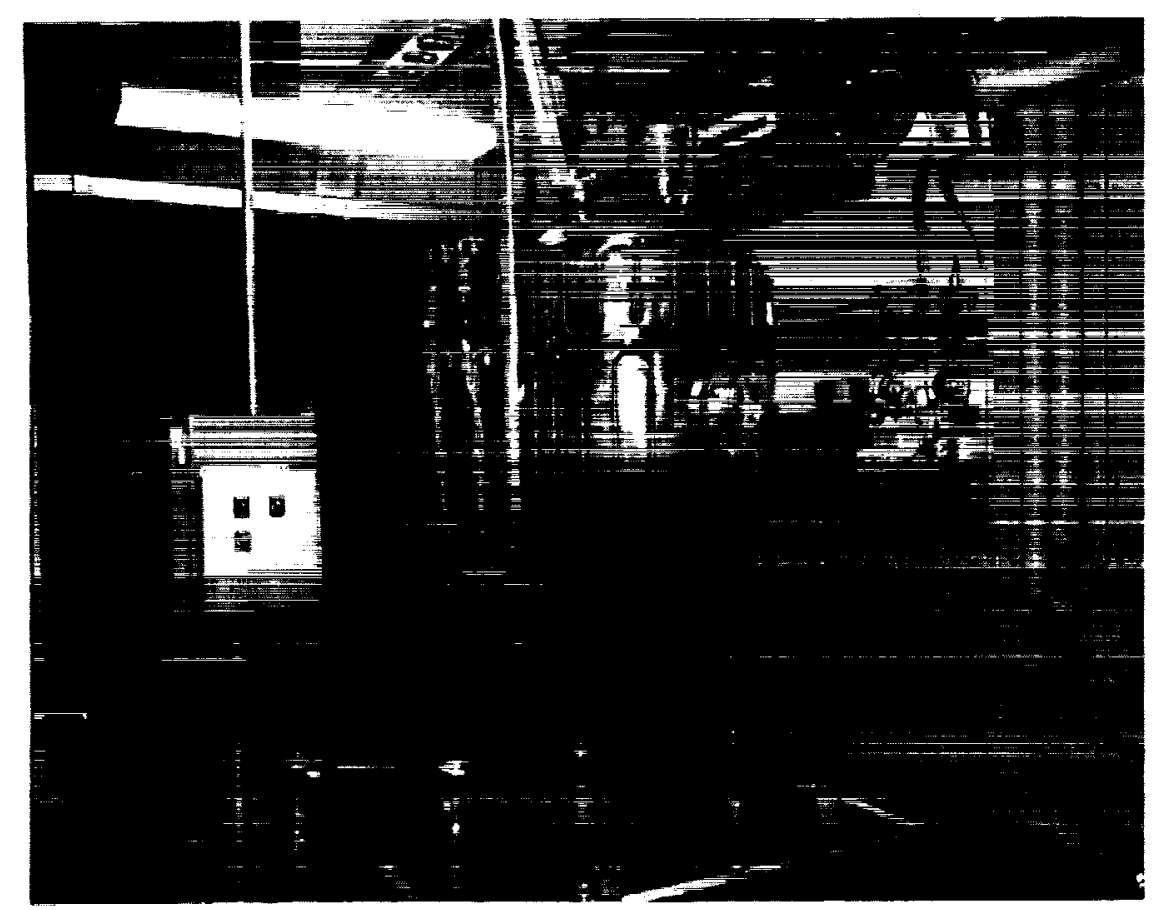

Figure 7. - Test tank with cold wall attached.

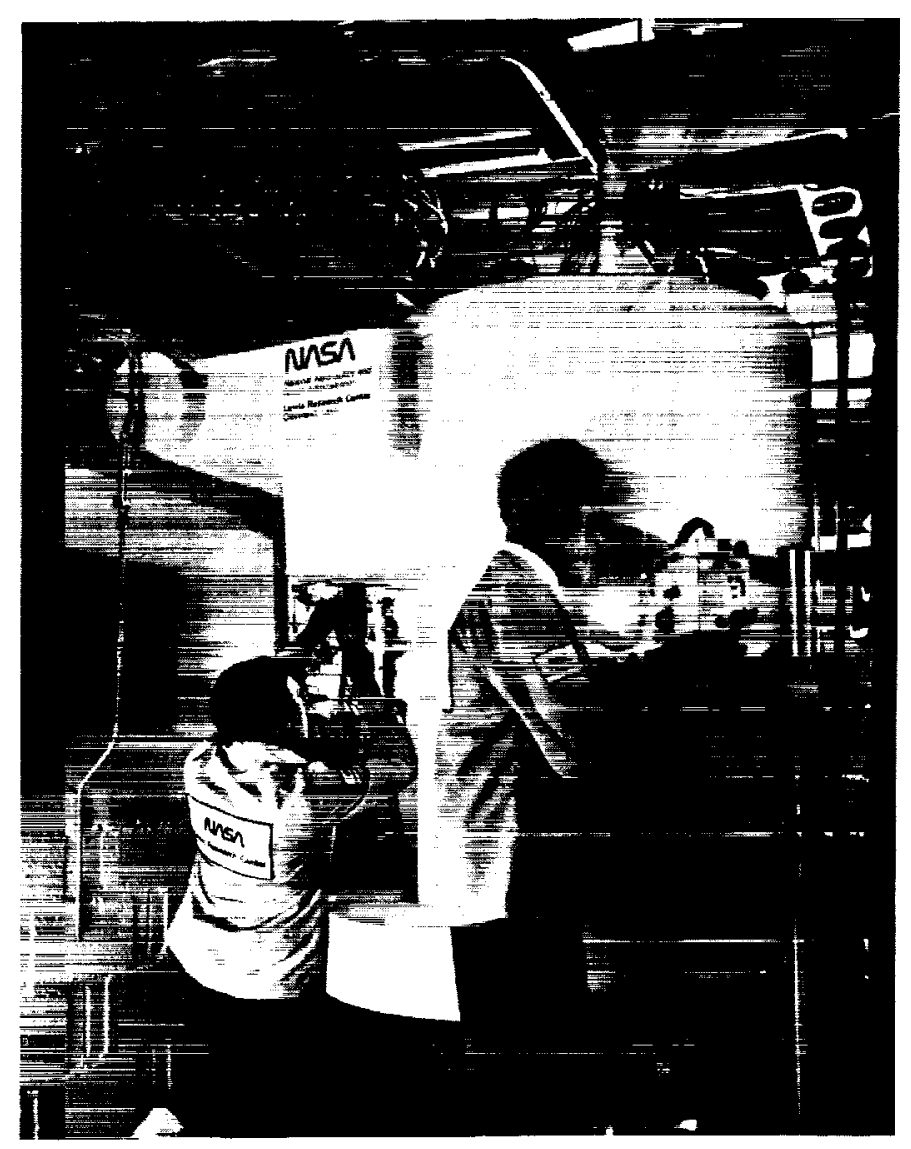

Figure 8. - Insulated test tank. 


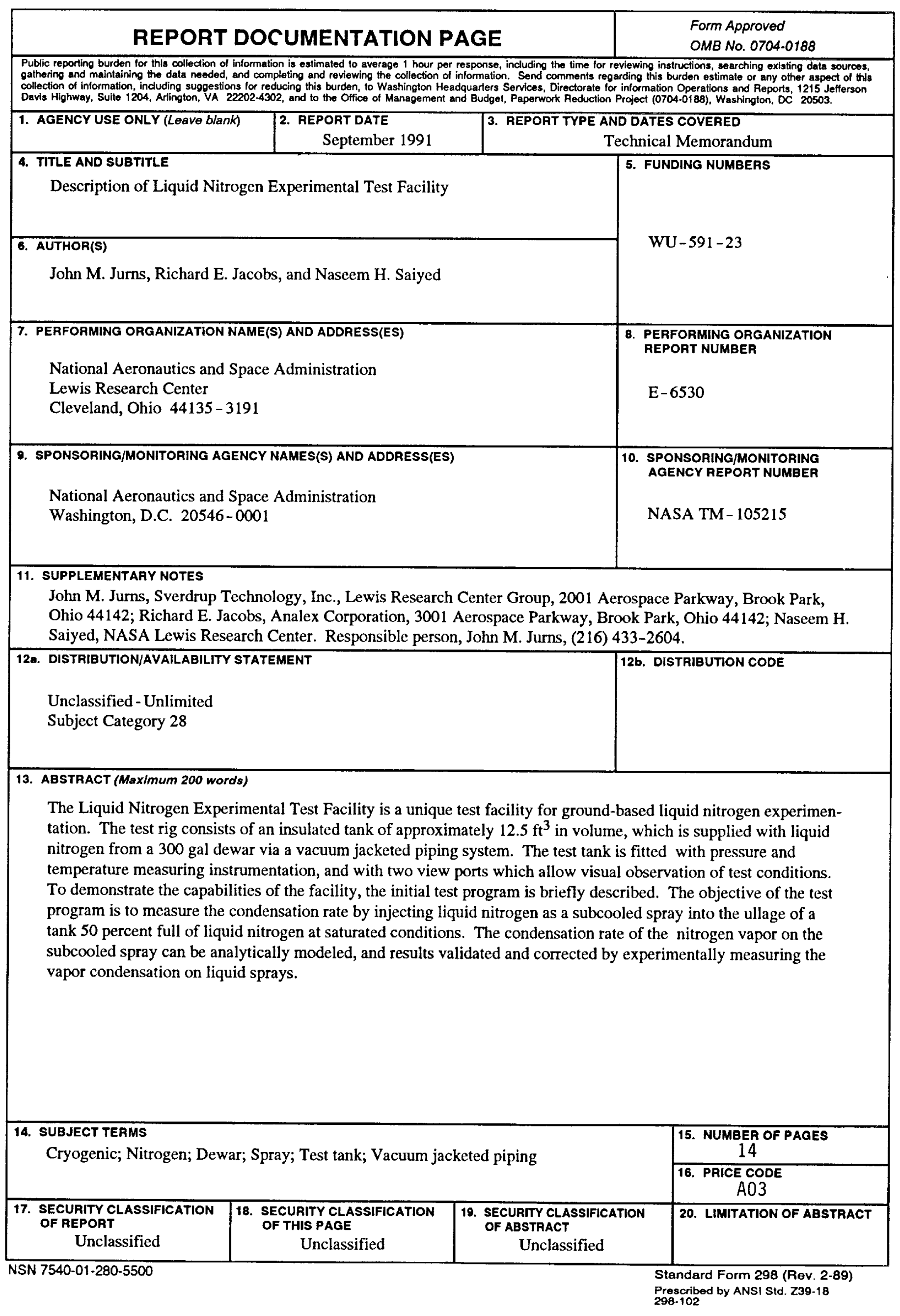


